\title{
I - ATA DA REUNIÃO DO DEPARTAMENTO DE HISTÓRIA DA FACULDADE DE FILOSOFIA DA UNIVERSIDADE DO PARANÁ, REALIZADA EM 2 DE DEZEMBRO DE 1964 [REGISTRANDO SUA CONSTITUIÇÃO EM PRINCÍPIOS DE MAIO DE 1959]
}

\begin{abstract}
The minute of the Department of History, Faculty of Philosophy (Science and Language), Paraná Federal University, that happened in December 2nd 1964 [and registered the course's foundation in early May 1959]
\end{abstract}

Às nove horas do dia 2 de dezembro de 1964, na sala do Departamento de História da Faculdade de Filosofia da Universidade do Paraná, reuniram-se em sessão os membros dêste Departamento, presidida pela sua diretora Professôra Cecília Maria Westphalen, e com a presença dos professôres Brasil Pinheiro Machado, Altiva Pilatti Balhana, Neusa de Castro Guimarães, Odah Regina Guimarães Costa, Oksana Boruszenko e Jayme Antonio Cardoso. Aberta a sessão, a Professôra Presidente comunicou que reassumia a direção do Departamento, dirigido pelo Professor Brasil Pinheiro Machado no período em que esteve a mesma a serviço do Ministério da Educação e Cultura. Em seguida propôs que as reuniões do Departamento passassem a ser registradas em Atas, dado o aumento considerável das atividades didáticas e de pesquisa e a conveniência de serem as suas deliberações ordenadas e registradas tendo em vista a reforma do Regimento da Faculdade que prevê como base da sua organização didática a existência dos departamentos. Propôs ainda fosse designado para secretariar a presente sessão o Professor Jayme Antonio Cardoso. Aprovadas ambas as indicações, usou ainda da palavra a Professôra Cecília Maria Westphalen, dizendo da conveniência de ser consignado na Ata da presente sessão um relato retrospectivo da vida do Departamento de História da Faculdade de Filosofia desde a sua constituição até o presente momento, o que foi por todos aprovado. Ainda com a palavra, a Professôra Cecília 
Maria Westphalen passa a relatar o histórico do Departamento, qual seja: - "Havendo a Professôra Cecília Maria Westphalen, em princípios de maio de 1959, regressado da Europa, onde, durante um ano, realizara estudos especializados e observações sôbre a vida universitária, principalmente na Alemanha e na França, propôs ela uma reunião dos Professôres de tôdas as disciplinas históricas da Faculdade de Filosofia da Universidade do Paraná, com o objetivo de constituir um Seminário de História, nos moldes dos seminários encontrados nas universidades alemãs, a fim de dinamizar e organizar os trabalhos docentes e discentes do curso de História desta Faculdade, bem como desenvolver um programa de pesquisas históricas dentro das atuais perspectivas metodológicas de História. Reunidos os Professôres convocados a 14 de maio de 1959 aprovaram êles o regulamento que a 18 de junho do mesmo ano, foi encaminhado à apreciação dos órgãos diretores da Faculdade, nos têrmos seguintes Regulamento do Seminário de História da Faculdade de Filosofia da Universidade do Paraná: Artigo $1^{\mathrm{o}}$.) - Os Professôres das Cátedras de História Moderna e Contemporânea, História Antiga e Medieval, História da América, História do Brasil, História da Filosofia, História da Educação e História das Doutrinas Econômicas, da Faculdade de Filosofia, Ciências e Letras da Universidade do Paraná, constituem um centro de estudos e pesquisas que terá a denominação "Seminário de História"; Artigo 2. ) - É finalidade do "Seminário de História" promover e realizar sessões de Seminário sôbre o ensino da História, a pesquisa histórica, a teoria da História, ou qualquer outro problema da ciência histórica; Artigo $3^{\circ}$.) - Para cumprir sua finalidade, o "Seminário de História" será composto por três Secções de Estudos: a) de Ensino da História; b) de Pesquisa da História; c) de Teoria da História. § único - Cada Secção será dirigida por um Diretor, cuja função é a de promover estudos e pesquisas históricas, como matéria preparatória para as sessões de Seminário. Para êste trabalho, o Diretor poderá convidar professôres da Universidade, professôres estranhos, pesquisadores, especialistas, ou qualquer estudioso da História; Artigo $4^{\circ}$.) - As sessões de Seminário serão didáticas, quando organizadas para o treinamento dos alunos dos Cursos de História da Faculdade de Filosofia, e científicas, ou no exame de problemas da ciência da História. Haverá, também, sessões de Seminário multidisciplinar, caso em que serão convidados especialistas de outras disciplinas, a fim de participarem da sessão; Artigo $5^{\circ}$.) - Os Professôres 
das Cátedras citadas no Artigo $1^{\circ}$., bem como seus Assistentes e Instrutores, constituem o Conselho do "Seminário de História", cuja competência é a seguinte: a) - Eleger o Diretor Geral e os Diretores de Secção e dar-lhes posse; b) - Dar assistência ao Diretor Geral e aos demais Diretores nos projetos de trabalhos e Seminário; c) - Aprovar a admissão de associados ao "Seminário de História". Artigo $6^{\circ}$.) - Além dos Professôres citados no Artigo anterior, poderão ser membros do "Seminário de História", como associados, outros professôres, pesquisadores, especialistas, ou qualquer estudioso da História, desde que sua admissão seja aprovada pelo Conselho; Artigo $7^{\circ}$.) - A direção geral do "Seminário de História" será exercida por um Diretor Geral, cuja competência será: a) - Promover, realizar e presidir as sessões de Seminário; b) - Organizar prèviamente o tema da sessão de Seminário e seu Regimento; c) - Convidar as pessoas que deverão tomar parte em cada sessão de Seminário; d) - Exercer atos de administração; e) - Representar o "Seminário de História" nas suas relações com as entidades universitárias e com pessoas e instituições estranhas à organização; § único - O mandato do Diretor Geral, como o dos Diretores de Secção, será de um ano; Artigo $8^{\circ}$.) - O “Seminário de História" promoverá cursos e conferências de extensão, e poderá assinar convênios ou acôrdos com instituições culturais; Artigo $9^{\circ}$.) - O "Seminário de História" promoverá a publicação dos trabalhos das Secções e a resenha das sessões de Seminário; Artigo $10^{\circ}$.) - O presente Regulamento deverá ser aprovado pelo Conselho Técnico-Administrativo da Faculdade de Filosofia, Ciências e Letras da Universidade do Paraná, e o "Seminário de História”, promoverá sua vinculação ao Conselho de Pesquisas da Universidade do Paraná, como órgão de pesquisas; Artigo $11^{\circ}$.) - O presente Regulamento entrará em vigor na data da sua aprovação pelo C.T.A. da Faculdade de Filosofia, Ciências e Letras da Universidade do Paraná e segue assinado pelos Professôres presentes à reunião de fundação do "Seminário de História".

Tal regulamento foi, porém, somente enviado pela direção da Faculdade à consideração do C.T.A. em 4 de dezembro de 1959. O Conselho TécnicoAdministrativo, porém, uma vez que na estrutura da Faculdade não existia instituição de Seminário, mas tão-somente de Departamentos, propôs a adaptação do mesmo a essa organização, o que foi feito, havendo já a 16 de janeiro de 1960, sido designado relator para o Regulamento de um Departamento de História, apresentado pelos Professôres de História, qual 
seja: - Artigo $1^{\circ}$.) - Fica instituído o DEPARTAMENTO DE HISTÓRIA, da Faculdade de Filosofia, Ciências e Letras da Universidade do Paraná, o qual em conformidade com o artigo $25^{\circ}$. do Regimento Interno da referida Faculdade, é integrado, inicialmente, pelas Cátedras de História Antiga e Medieval, Moderna e Contemporânea, História do Brasil e História da América. Artigo $2^{\circ}$.) - A qualquer tempo, ouvido o Conselho de Professôres do Departamento, poderão vir a integrá-lo outras Cátedras e disciplinas que não figuram entre aquelas da sua organização inicial. § único - A inclusão de novas Cátedras e disciplinas, de que trata o presente artigo, far-se-á mediante proposição do Conselho de Professôres do DEPARTAMENTO DE HISTÓRIA, ao Conselho Técnico-Administrativo da Faculdade. Artigo $3^{\circ}$.) - É finalidade precípua do DEPARTAMENTO DE HISTÓRIA, promover e realizar a pesquisa histórica, notadamente a regional, o estudo da teoria da História, sessões de seminário sôbre o ensino da História ou qualquer outro problema da ciência histórica. Artigo $4^{\circ}$.) - A fim de cumprir sua finalidade, compete ao DEPARTAMENTO DE HISTÓRIA: a) - Estimular o progresso no ensino da História, e os trabalhos de investigação científica nos diversos setôres das Cátedras que o constituem; b) - Estabelecer e pôr em execução medidas que contribuam para a melhor coordenação e eficiência das atividades didáticas das Cátedras que o constituem; c) Planejar e realizar pesquisas teóricas e de campo, com a participação de cientistas e técnicos interessados; d) - Promover a máxima participação dos alunos da Faculdade, Curso de História, em tôdas as atividades do Departamento, e facilitar-lhes por meio de bolsas de estudos ou outros recursos, a dedicação integral à carreira científica; e) - Promover sessões de seminários, mesas-redondas, colloquiuns, debates e outras, sôbre temas da ciência histórica e do ensino da História; f) - Publicar os resultados dos trabalhos realizados pelo Departamento e as resenhas das sessões de seminário; g) - Organizar: 1. Acêrvo de documentação bibliográfica, iconográfica, estatística, cartográfica, etc...; 2. Acêrvo de documentação sôbre a história regional; 3. Filmoteca, fototeca e discoteca especializadas; 4. Coleções históricas e o Museu de História; 5. Biblioteca especializada. h) - Proporcionar, por meio de conferências, de projeções, e de exposições, ampla divulgação dos conhecimentos históricos; i) - Divulgar, por meio de palestras, os resultados dos trabalhos realizados pelo Departamento. Artigo $5^{\circ}$.) - Para melhor realizar suas funções, o DEPARTAMENTO DE 
HISTÓRIA será composto por Secções de Estudos e Trabalhos, a saber: a) - Secção de Ensino da História; b) - Secção de Pesquisa Histórica; c) Secção de Teoria da História. § primeiro - Com o surgir de novas necessidades, poderão ser criadas novas Secções de Estudos e Trabalhos, mediante proposição e aprovação do Conselho de Professôres do Departamento; § segundo - Cada Secção de Estudos e Trabalhos será dirigida por um Diretor, eleito pelo Conselho de Professôres do Departamento, e a êle competirá a direção imediata dos trabalhos da Secção. Artigo $6^{\circ}$.) - O Professôres das Cátedras citadas no Artigo $1^{\circ}$., bem como os seus Assistentes e Instrutores, constituem o Conselho de Professôres do DEPARTAMENTO DE HISTÓRIA, cuja competência é: a) - Exercer, como órgão deliberativo e consultivo, jurisdição sôbre o Departamento; b) - Elaborar ou modificar o Regulamento do Departamento, submetendo-o à aprovação do Conselho Técnico-Administrativo da Faculdade; c) - Eleger o Diretor Geral do Departamento e os Diretores de Secções; d) - Baixar normas regulamentais quando assim o exigir o funcionamento das Secções e serviços do Departamento; e) - Organizar e aprovar anualmente o plano de pesquisas e trabalhos a serem realizados; f) - Organizar e aprovar a proposta orçamentária anual do Departamento; g) - Aprovar a realização dos cursos anualmente promovidos pelo Departamento; h) - Apreciar e aprovar o Relatório Anual do Diretor Geral do Departamento com os respectivos relatórios parciais das Secções; i) - Solicitar a lotação de funcionários administrativos à Direção da Faculdade, mediante proposta do Diretor Geral e Diretores de Secções; j) - contratar, mediante verbas próprias do Departamento, o pessoal necessário á realização dos seus trabalhos; k) - Resolver sôbre a aceitação de legados e donativos; 1) - Aprovar as publicações que devem ser feitas anualmente; $\mathrm{m}$ ) - Aprovar e propor ao Conselho Técnico-Administrativo da Faculdade, a admissão de novas Cátedras disciplinas no Departamento; n) - Aprovar a criação de novas Secções de Estudos e Trabalhos; o) - Deliberar sôbre as questões omissas no presente Regulamento. Artigo $7^{\circ}$.) - A direção geral do DEPARTAMENTO DE HISTÓRIA será exercida por um Diretor Geral, eleito trienalmente pelo Conselho de Professôres do Departamento, entre os Professôres Catedráticos do Curso de História que compõem o Departamento. § primeiro - A eleição do Diretor Geral do Departamento, bem como dos Diretores de Secções, realizar-se-á durante a segunda quinzena do mês de novembro, e entrarão êles no exercício das 
suas funções no dia $1^{\circ}$. de março do ano seguinte ao da sua eleição. $\S$ segundo - Somente poderá ser renovado o mandato do Diretor Geral do Departamento, e dos Diretores de Secção, por um período administrativo subsequente mediante dois terços da totalidade dos votos do Conselho de Professôres. § terceiro - O mandato dos Diretores de Secção será igualmente de três anos, sendo que poderão ser eleitos Professôres Catedráticos, Assistentes ou Instrutores. Artigo $8^{\circ}$.) - Compete ao Professor Diretor Geral do Departamento: a) - Convocar e presidir as reuniões do Conselho de Professôres e do pessoal do Departamento; b) - Coordenar as atividades didáticas e científicas do Departamento de acôrdo com as resoluções aprovadas; c) - Administrar o Departamento; tomando as providências necessárias à plena realização de suas atividades; d) - Representar o DEPARTAMENTO DE HISTÓRIA junto à Direção da Faculdade de Filosofia e demais autoridades universitárias, e em todos os atos, dentro ou fora da Universidade, a que o Departamento tenha de comparecer. Artigo $9^{\circ}$.) - O DEPARTAMENTO DE HISTÓRIA terá um Secretário que será designado pelo Diretor Geral do Departamento, entre Licenciados em História, o qual ficará diretamente subordinado a aquêle Diretor Geral. § único - O Secretário do Departamento terá o número de auxiliares que se tornarem necessários com o desenvolvimento das atividades do Departamento. Artigo $10^{\circ}$.) - As despêsas decorrentes do funcionamento do DEPARTAMENTO DE HISTÓRIA correrão por conta das dotações constantes, anualmente, do orçamento da Universidade do Paraná, e dos auxílios que lhe forem concedidos pelas instituições oficiais ou particulares de assistência ao ensino e à pesquisa. Artigo $11^{\circ}$.) - Passa a funcionar no DEPARTAMENTO DE HISTÓRIA, a Secção de História do Instituto de Pesquisas da Faculdade de Filosofia, Ciências e Letras. Artigo $12^{\circ}$.) - O funcionamento da biblioteca, mapoteca e outros serviços do Departamento, será regido por normas específicas baixadas pelo Conselho de Professôres. Artigo $13^{\circ}$.) - Poderão participar dos trabalhos científicos e didáticos do DEPARTAMENTO DE HISTÓRIA, como membros associados ou colaboradores, outros professôres, pesquisadores, especialistas, ou qualquer estudioso da História, desde que a sua admissão seja aprovada pelo Conselho de Professôres. Artigo $14^{\circ}$.) - O DEPARTAMENTO DE HISTÓRIA para melhor cumprir sua finalidade e ampliar suas atividades poderá assinar convênios ou acordos com instituições culturais e órgãos governamentais, de conformidade 
com a legislação em vigor. Artigo $15^{\circ}$.) - Os recursos do pessoal universitário do Departamento, contra atos da sua administração, serão julgados em primeira instância pelo Conselho de Professôres, e instância superior ficam subordinados ao Conselho Técnico-Administrativo da Faculdade, respeitadas as disposições do Regimento da Faculdade de Filosofia, Ciências e Letras da Universidade do Paraná. Artigo $16^{\circ}$.) - O DEPARTAMENTO DE HISTÓRIA praticará sob sua exclusiva responsabilidade, todos os atos peculiares ao seu funcionamento. Artigo $17^{\circ}$.) - Os assuntos de ordem administrativa ou didática não regulamentados de modo especial no presente Regulamento, serão regidos pelas normas estabelecidas no Regimento Interno da Faculdade de Filosofia, Ciências e Letras da Universidade do Paraná, e nos Estatutos da Universidade do Paraná. Artigo 18.) O presente Regulamento do DEPARTAMENTO DE HISTÓRIA entrará em vigor na data da sua aprovação pelo Conselho Técnico-Administrativo da Faculdade de Filosofia, Ciências e Letras da Universidade do Paraná. ___ Enquanto era aguardada a regularização do Seminário de História junto aos órgãos diretores da Faculdade, davam início os Professôres de História às atividades do mesmo, planejando a realização, com a participação de inúmeros professôres e estudiosos da História do Paraná, de um seminário para a revisão da Historiografia do Paraná. Foi assim, marcada para 23 de setembro de 1959 a primeira sessão dêste seminário, objetivando a análise da obra dos historiadores do Paraná, com a crítica das suas fontes, métodos e técnicas de trabalho e com a finalidade de realizar o levantamento da situação real da Historiografia Regional do Paraná, e dos problemas que nela restam por serem equacionados e resolvidos. Esta primeira sessão teve como relator o Professor Brasil Pinheiro Machado, que examinou a obra "História do Paraná" de Romário Martins, com base nos seguintes pontos: 1. Brevíssimo resumo do livro "História do Paraná", de Romário Martins, 3ª edição. 2. A crítica a ser feita pelo Resenhista tem como finalidade o estabelecimento de um sistema de referência para se construir a História do Paraná, e abrange, principalmente, os seguintes pontos: a) - O conceito de história regional, dentro do complexo da História do Brasil. b) - Cada uma dessas histórias regionais tem uma "ambientação" que a diferencia das outras. c) - A possibilidade, no estado atual de pesquisas, de se escrever uma história geral do Paraná. d) - O estado atual da pesquisa histórica regional do Paraná. e) O meio geográfico como fator da história regional. O Professor Brasil 
Pinheiro Machado, de acôrdo com o referido documento, procedeu à resenha da História do Paraná, de Romário Martins, analisando os pontos capitais de cada um dos Capítulos da referida obra. Em seguida passou à crítica da obra de Romário Martins, tendo como finalidade o estabelecimento de um sistema de referências para se construir a História do Paraná, abrangendo, principalmente, os pontos seguintes: a) - O conceito de história regional, dentro do complexo da História do Brasil, dizendo da necessidade de se fazer a história dos grupos humanos regionais, da adoção de um regionalismo social e não um regionalismo simplesmente geográfico. b) - Cada uma dessas histórias regionais tem uma "ambientação" que a diferencia das outras, usando o têrmo no sentido de caracterização, como sobretudo no sentido de espaço social. c)-A possibilidade, no estado atual das pesquisas, de se escrever uma história geral do Paraná. Tal história somente poderá ser realizada quando precedida de grande número de estudos monográficos, com um trabalho mais amplo e profundo de pesquisa da história regional. d) - O estado atual da pesquisa histórica regional do Paraná, dizendo da estreiteza das fontes históricas, e da necessidade do seu levantamento e utilização racional. e) - O meio geográfico como fator da história regional, salientando a importância do estudo do meio. Finalmente, o Professor Brasil Pinheiro Machado disse que apesar das suas limitações, a obra de Romário Martins é fundamental para o historiador do Paraná, uma vez que êle abriu caminhos e apontou os rumos, tal como Varnhagem, para a História do Brasil. Dando início à participação dos inscritos, o Professor João José Bigarella procedeu à análise do capítulo da obra de Romário Martins, com referência do meio geográfico, notando o quase desconhecimento não só do autor, como da sua época, sôbre a Geografia Física. O seu capítulo é mais apenas uma simples relação de acidentes geográficos. Apontou ainda o Professor Bigarella, diversos pontos da obra de Romário Martins que precisam ser revistos, uma vez que já provados serem inexatos. A seguir usou da palavra o Professor José Loureiro Fernandes que tratou do capítulo referente às populações indígenas do Paraná. Disse o Professor Loureiro Fernandes, que, ainda, em trabalhos publicados posteriormente, são encontradas as falhas de Romário Martins, com relação à enumeração dos grupos pertencentes aos Gê. Assim, por exemplo, Romário Martins dá como grupos diversos Caiués e Caiuás, que se tratam apenas de grupos Caingangs exogâmicos. Disse o Professor Loureiro Fernandes que no es- 
tudo das populações indígenas, se deverá levar em conta não apenas a sua distribuição no espaço, mas também no tempo. Salientou que ainda se está muito longe de poder escrever o Capítulo das populações indígenas no Paraná e na necessidade de um grande número de monografias especializadas preliminares. Comunicou a todos que graças aos trabalhos do Centro de Pesquisas Arqueológicas da Universidade do Paraná, já se poderá pelo Processo do Carbono 14, determinar a sucessão de algumas das culturas indígenas do Paraná. Finalmente, salientou a importância da necessidade de correlacionar-se o ambiente geográfico e o elemento humano. A seguir usou da palavra a Professôra Cecília Maria Westphalen, que focalizou: $1^{\circ}$.) - o conceito de História Regional, fundado no conceito de região, como área geogràficamente definida, mas caracterizada por elementos culturais que lhe conferem relativa homogeneidade; $2^{\circ}$.) - falou da sua preferência pelo conceito de caracterização em lugar de ambientação; $3^{\circ}$.) - sôbre o conceito de História Geral, que não pode significar simplesmente uma soma de histórias particulares. Ela supõe uma composição unitária que estende seu âmbito tanto no tempo como no espaço; ela exige assim, sobretudo, unidade e estruturação. Falando em têrmos de estruturação, a Professôra Cecília Maria Westphalen disse da necessidade de precisar-se o conceito de estrutura, notadamente das estruturas temporais. Disse ainda da dificuldade de dar-se estruturação à história geral, quando não se conhecem as estruturas, isto é, as realidades sociais de permanência nos diferentes momentos da evolução da sociedade paranaense. Falou ainda sôbre o estado atual da pesquisa histórica regional, onde tudo ou quase tudo resta por fazer, sobretudo no domínio da economia histórica. Disse, finalmente, da necessidade de serem reexaminadas as fontes da história paranaense, bem como da necessidade do emprêgo de novas técnicas quantitativas no tratamento das mesmas. A seguir, usou da palavra o Professor Júlio Moreira, que se reportou à necessidade de serem realizadas pesquisas documentais, acêrca da História do Paraná no Arquivo Nacional e em arquivos de São Paulo e de Santa Catarina. O Professor Carlos Stellfeld referiu-se na sua intervenção, ao problema da datação do povoamento do Paraná. Com a palavra, a Professôra Altiva Pilatti Balhana disse também da necessidade do reexame dos dados sôbre o movimento imigratório no Paraná e do tratamento estatístico dos mesmos. Trabalho êsse de grande utilidade, não só para o melhor conhecimento da intensidade, composição e regularidade 
do fluxo imigratório para o Paraná, mas também uma valiosa contribuição para a revisão do movimento geral de imigrantes entrados no Brasil. Autoridades em problemas migratórios têm encarecido a necessidade imperiosa dos pesquisadores tomarem o problema numérico de imigrantes com espírito crítico, procurando utilizar de maneira ampla e completa quanto possível as fontes primárias existentes. Indispensável também, nesse reexame, será o cálculo do coeficiente de fixação, o qual deverá ser examinado, não apenas tendo em vista as entradas e saídas do país, mas também em relação ao local a que se dirigiram. Disse ainda a Professôra Altiva Pilatti Balhana que as observações de Romário Martins na obra "História do Paraná", sôbre a evolução do comércio paranaense e suas transformações, constituem hipóteses de trabalho que poderão ser valiosos pontos de partida para estudos aprofundados segundo novas técnicas quantitativas. Finalmente disse que o importante tema da contribuição cultural das novas etnias foi naquela obra ignorado. Esta é, porém, uma preocupação relativamente recente que está condicionada à aceitação do conceito antropológico de cultura. No entanto, disse a Professôra Altiva Pilatti Balhana, é trabalho que deve ser feito ampliando e aprofundando algumas análises sôbre italianos, alemães e poloneses, recentemente realizadas. Com a palavra, o Professor Liguaru Espírito Santo, refere que em sua obra Romário Martins olvidou o ângulo educacional da História do Paraná, e o Professor Osvaldo Pilotto disse da necessidade de serem realizadas novas pesquisas de História Regional do Paraná. Novamente com a palavra o Professor Brasil Pinheiro Machado teceu considerações sôbre a personalidade e a obra de Romário Martins, que foi sem dúvida um pesquisador, um heurístico que marcou caminho na elaboração da História do Paraná. Finalmente apontou como os principais problemas levantados nesta sessão, $1^{\circ}$.) - conceito de estrutura; $2^{\circ}$.) - necessidade do reexame e estudo comparativo das fontes; $3^{\circ}$.) - necessidade de um sistema de referências para a construção da História do Paraná; $4^{\circ}$.) - necessidade de desenvolvimento de maiores pesquisas com bases em fontes primárias e consequente elaboração de monografias especializadas; $5^{\circ}$.) - a contribuição que o emprêgo de novas técnicas metodológicas poderá trazer à ampliação dos conhecimentos de História do Paraná. Com a formulação dêsses problemas, foi a sessão encerrada.

Somente em 11 de junho de 1960 foi o Regulamento do Departamento de História aprovado pelo Conselho Técnico Administrativo. Face a êste 
Regulamento, reunidos os Professôres das cadeiras de História Antiga e Medieval, História Moderna e Contemporânea, História da América e História do Brasil, foi a Professôra Cecília Maria Westphalen eleita sua primeira diretora. Foram para êste ano elaborados os primeiros projetos de pesquisa a serem desenvolvidos pelo Departamento com o auxílio previsto no artigo 18 do Regulamento do Conselho de Pesquisas da Universidade do Paraná, quais sejam: $1^{\circ}$.) - Pesquisa e levantamento, sob a direção do Professor Brasil Pinheiro Machado, a serem realizados em arquivos de família, arquivos paroquiais, arquivos judiciários, e outros, que possam constituir fontes para a historia regional do Paraná; $2^{\circ}$.) - Pesquisa e levantamento do comércio importador e exportador do Paraná, através do pôrto de Paranaguá, no século XIX, sob a orientação da Professôra Cecília Maria Westphalen. Neste ano de 1960 foram providenciadas as instalações da sala de seminário, biblioteca e leitura do Departamento de História. Em 1960 foi objeto da consideração e luta dos professôres do Departamento de História em favor da separação dos cursos de História e Geografia, ainda unidos nesta Faculdade. Em julho dêste mesmo ano, preparados por seus respectivos professôres, um grupo de estudantes do curso de História, participou em São Paulo do I Congresso Nacional de Universitários de História. Como recomendação dêsse Congresso foi, e com o incentivo do Departamento de História, fundado o Centro de Estudos de História, que congrega os alunos do curso de História desta Faculdade. No mês de outubro de 1960, em colaboração com a Diretoria da Faculdade, o Departamento de História programou comemorações "Henriquinas", destacando-se a conferência realizada pelo Professor Suares Amora da Faculdade de Filosofia da Universidade de São Paulo, sôbre "Os cronistas de D. João I" e a realização de uma exposição "Henriquina" na sala do Departamento de História com livros e material especialmente preparados e do mais alto valor histórico. Ainda em novembro de 1960, especialmente convidado, recebeu o Departamento de História, a visita do Professor Eduardo de Oliveira França da Faculdade de Filosofia da Universidade de São Paulo, que falou sôbre "Relações entre a História e a Geografia", havendo ainda participado de um seminário com os professôres do Departamento de História. Nas atividades docentes extracurriculares, neste mesmo mês de novembro, a Professôra Cecília Maria Westphalen, proferiu palestra na Casa de Portugal em São Paulo sôbre a eleição do Mestre de Avis, por ocasião 
do colóquio comemorativo do centenário do Infante D. Henrique As atividades do Departamento de História no ano de 1961, foram consignadas no relatório anual enviado à direção da Faculdade de Filosofia e que segue transcrito: "Relatório das atividades do ano de $1961-1$. Atividades de pesquisa: a) - O Projeto de pesquisa referente ao "Comércio Exportador e Importador do Paraná, através do pôrto de Paranaguá", sob a direção da Professôra Cecília Maria Westphalen, teve acelerado o seu ritmo de trabalho. Foram examinados, no Arquivo do Estado de São Paulo, todos os "Livros de Barreiras" e selecionados para microfilmagem cêrca de 2.250 documentos. Esta microfilmagem foi procedida e já os referidos microfilmes se encontram, em grande parte, transcritos e em fase de estudos. O período coberto por êste levantamento foi o da primeira metade do século XIX. Com parte dêste material coletado foi possível a elaboração de alguns quadros gerais, encontrando-se os mesmos em fase de revisão, após o que poderão ser publicados primeiros resultados parciais desta pesquisa. Teve prosseguimento ainda o levantamento de dados e informações contidas em Relatórios e Mensagens de Presidentes da Província e Governadores do Estado do Paraná, no período referente à segunda metade do Século XIX, achando-se o mesmo em vias de conclusão. b) - Foi iniciado o Projeto de pesquisa referente à história demográfica do Paraná, sob a direção da Professôra Altiva Pilatti Balhana. Foram examinadas, no Arquivo do Estado de São Paulo, as Caixas referentes à "População", da zona do litoral do Paraná, ou seja do povoamento tradicional. Foram selecionados para microfilmagem cêrca de 850 documentos. Esta microfilmagem foi procedida e os fotogramas encontram-se em fase de leitura e transcrição. c) - A pesquisa sôbre os russos brancos, recentemente estabelecidos nos Campos Gerais, foi iniciada, desenvolvendo-se através das atividades seguintes: Levantamento da documentação existente, relatórios da Divisão de Imigração da Secretaria de Agricultura do Estado do Paraná, do representante do CIME no Paraná e outros. Preparação material da pesquisa, elaboração de cartografia, documentação fotográfica, questionários e roteiros para os trabalhos de campo, etc.. Foram ainda realizadas viagens de reconhecimento aos núcleos coloniais, contactos com personalidades locais, realização de entrevistas com as mesmas e outras personagens ligadas aos referidos núcleos. Êste Projeto está sendo desenvolvido sob a direção dos Professôres Brasil Pinheiro Machado e Altiva Pilatti Balhana, constituindo 
parte de um Projeto de amplitude maior referente ao estudo das transformações da estrutura agrária dos Campos Gerais. d) - Teve prosseguimento também o Projeto de pesquisa referente à história regional, dirigido pelo Professor Brasil Pinheiro Machado. Visando ordenar os trabalhos de levantamento, em arquivos que constituem fontes da história regional, deu-se prioridade às fontes da história social e econômica do grupo de fazendeiros criadores de gado que desbravou os Campos Gerais, os campos de Guarapuava, de Palmas, do Erê e do Nonohay, e nesses campos construiu uma estrutura social que se desorganizou desde o final do século passado. De acôrdo com êsse ordenamento, deu-se continuidade, no ano de 1961, ao levantamento dos inventários referentes ao final do século XVIII e ao século XIX, existentes nos arquivos judiciários da Comarca de Castro. d) - Teve prosseguimento ainda o Projeto de pesquisa, sob a direção da Professôra Altiva Pilatti Balhana, referente ao estudo sôbre "O comportamento político dos colonos de Santa Felicidade". Foi, no decorrer do ano de 1961, concluído o levantamento de dados, iniciado o tratamento estatístico dos mesmos, e procedida a elaboração gráfica. 2-Atividades Didáticas: a) - Cursos regulares: Tôdas as cadeiras e disciplinas do Curso de História funcionaram regularmente, ministradas as aulas com assiduidade por parte de professôres e alunos. Trabalhos práticos foram realizados em tôdas as cadeiras de História, com o máximo aproveitamento. A prática de Seminários foi incentivada, tornando-se já uma instituição regular e habitual aos alunos do Curso de História. Êstes Seminários, dos mais variados tipos, foram disciplinares, mas sobretudo interdisciplinares. b) - Cursos extraordinários: Com a separação dos Cursos de Geografia e História e a consequente criação de novas disciplinas, os Professôres Brasil Pinheiro Machado e Cecília Maria Westphalen, sem quaisquer ônus para a Universidade do Paraná, prelecionaram respectivamente, em todo o decorrer do ano letivo, as disciplinas de Princípios de Sociologia e Introdução à História. c) - Palestras, conferências e cursos: Especialmente convidada, a Professôra Cecília Maria Westphalen, no mês de março de 1961, proferiu a aula inaugural da Faculdade de Filosofia, Ciências e Letras de Londrina. Proferiu ainda palestra, no mês de Setembro, no Centro de Estudos Históricos, sob o título "A arte pictórica de Miguel Ângelo". No mês de agôsto proferiu Conferência, na Faculdade de Filosofia, sob o título "A unificação nacional italiana". Três Professôres do Departamento de História colaboraram 
com o Instituto de Ciências Sociais da Universidade do Paraná, ali proferindo Conferências, dentro do Curso de Noções básicas de Ciências Sociais, tais foram: Professor Brasil Pinheiro Machado que falou sôbre "Princípios gerais de Sociologia", Professôra Altiva Pilatti Balhana que falou sôbre "Demografia"; e Professôra Cecília Maria Westphalen que falou sôbre "A História como Ciência Social". O Professor Brasil Pinheiro Machado proferiu palestra no Centro de Estudos Históricos, no mês de Outubro, sôbre "A inquietação metodológica da História". Colaborando com a Cátedra de História do Brasil, a Professôra Altiva Pilatti Balhana prelecionou ali um Curso paralelo sôbre "Os imigrantes na formação histórica da sociedade

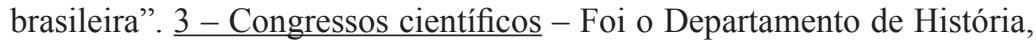
por seus professôres, especialmente convidado a comparecer e tomar parte nos trabalhos da XVI Assembleia Geral da Associação dos Geógrafos Brasileiros, na cidade de Londrina. Ali comparecendo, as Professôras Cecília Maria Westphalen, Altiva Pilatti Balhana e Odah Regina Guimarães Costa, participaram ativamente dos trabalhos de campo, auxiliando as equipes no que dizia respeito sobretudo ao assessoramento em matéria histórica. A Professora Altiva Pilatti Balhana participou ainda do Simpósio sôbre Colonização, apresentando o trabalho "Notas sôbre os núcleos recentes de colonização nos Campos Gerais". Convocado pela Faculdade de Filosofia de Marília, realizou-se no decorrer do mês de Outubro o I Simpósio dos Professôres de História do Ensino Superior. O Departamento de História da Faculdade de Filosofia da Universidade do Paraná, juntamente com os Departamentos de História das Faculdades de Filosofia da Universidade do Brasil e de São Paulo, foram convidados para constituírem as equipes de trabalho encarregadas da elaboração dos Relatórios científicos do Simpósio. Assim, as Professôras Altiva Pilatti Balhana e Cecília Maria Westphalen participaram das reuniões de equipes de estudos, realizadas prèviamente em São Paulo. Ao Simpósio de Marília compareceram as Professôras Altiva Pilatti Balhana, Neusa de Castro Guimarães e Cecília Maria Westphalen, sendo que a bancada paranaense participou ativamente de todos os trabalhos científicos da reunião. 4-Visitantes $-O$ Departamento de História recebeu a visita do Professor Jean Roche, Diretor do Instituto de Estudos Brasileiros, da Universidade de Toulouse. O ilustre Professor participou de um Seminário sôbre "Técnicas de Pesquisa Social", com os Professôres do Departamento de História, bem como proferiu uma Conferência, na Facul- 
dade de Filosofia, sôbre “A Colonização Alemã no Rio Grande do Sul”. O Departamento de História recebeu ainda a visita do Professor Guy de Hollanda, Docente-Livre da Faculdade de Filosofia da Universidade do Brasil que participou, também, de um Seminário com os Professôres dêste Departamento, sôbre "Situação das fontes históricas no Brasil" e proferiu uma Conferência sôbre "Problemas da pesquisa histórica no Brasil". $\underline{5 \text {-Come- }}$ morações - No seu programa de atividades didáticas, o Departamento de História incluiu a comemoração de datas históricas significativas. Assim, no decorrer do ano de 1961, escolheu a data do Centenário da Unificação Nacional Italiana para estas comemorações. Foi preparada exposição bibliográfica e de fotocópias de documentos, sôbre aquêle evento, a qual foi inaugurada pelo Sr. Cônsul da Itália no Paraná. Na mesma data, a Professôra Cecília Maria Westphalen proferiu Conferência sôbre a "Unificação Nacional Italiana". Ainda, os alunos do $3^{\circ}$. ano do Curso de História, desenvolveram estudos e trabalhos práticos sôbre o mesmo assunto, cujos resultados foram apresentados em sessões de Seminário. $\underline{6 \text { - Publicações }}-\mathrm{O}$ Departamento de História deu início no ano de 1961, com o trabalho "Os imigrantes na formação histórica da sociedade brasileira", da Professôra Altiva Pilatti Balhana, a publicação da sua Série Didática. Esperamos que as publicações da Série Científica possam ter início no ano de 1962, com os resultados de pesquisas desenvolvidas pelos Professôres do Departamento. 7 - Biblioteca - A Biblioteca do Departamento tomou grande impulso no decorrer do ano letivo, com a aquisição de novas obras ou com a vinda de volumes da Biblioteca Central da Faculdade. As entradas de livros na Biblioteca, no ano de 1961, somaram 556 volumes de livros e revistas. As consultas, ou seja o número de leitores, alcançou durante o ano a soma de 357, sendo a sua maior concentração durante os mêses de maio, junho, setembro e outubro. 8 - Secretaria - Embora sem um Secretário administrativo, a Secretaria do Departamento funcionou regularmente. Foi grande o movimento de correspondência com a Direção da Faculdade, da Universidade, com Faculdades e Universidades do País e do Exterior. A Secretaria do Departamento encarregou-se do intercâmbio de livros, sendo de notar aquêles realizados com o Instituto de História da Universidade do México, com o Departamento de História da Universidade de São Paulo. $\underline{9}$ - Centro de Estudos Históricos - O Departamento de História incentivou, por todos os meios ao seu alcance, o Centro de Estudos Históricos dos 
alunos do Curso de História da Faculdade de Filosofia. Uma delegação de alunos compareceu à II Reunião dos Centros de Estudos de História, realizada em Belo Horizonte, sendo que todos os membros da Delegação paranaense apresentaram trabalhos que foram todos aprovados, alguns até mesmo com louvor. O Centro de Estudos Históricos, no decorrer do segundo semestre, realizou uma série de palestras, proferidas por Professôres do Curso e outros especialmente convidados. 10 - Aquisições - A mais importante aquisição do Departamento de História no ano de 1961 foi a do aparelho de leitura de microfilmes. Aquisição esta de extrema necessidade e oportunidade, tanto que no decorrer dêste mesmo ano, foram já microfilmados cêrca de três mil documentos históricos, cuja leitura e transcrição estão sendo procedidas. Êstes fotogramas referem-se às pesquisas em andamento no Departamento de História. 11 - Pessoal - Todos os trabalhos do Departamento de História foram desenvolvidos pelos próprios Professôres. Na parte administrativa e, no projeto de pesquisa referente à vida econômica do Paraná, seu comércio exportador e importador através do pôrto de Paranaguá, foram auxiliados pela Licenciada Odah Regina Guimarães Costa. Os trabalhos da Biblioteca do Departamento foram também atendidos pela referida Professôra que realizava expediente diário das 14 às 18 horas." As atividades do Departamento de História no ano de 1962, foram consignadas no relatório anual enviado à direção da Faculdade de Filosofia e que segue transcrito = "Relatório das atividades do ano de 1962 1. Atividade de Pesquisa - a) - O projeto referente ao "Comércio Importador e Exportador do Paraná, através do pôrto de Paranaguá”, sob a direção da Professôra Cecília Maria Westphalen, teve prosseguimento. Foi completada a busca nas caixas de documentação referente a Paranaguá, existentes no Departamento do Arquivo do Estado de São Paulo, e microfilmadas as peças de interêsse ainda encontradas. Os microfilmes relativos à Paranaguá já se encontram em fase final de leitura e transcrição. Foi também elaborado, como amostragem do Projeto que está sendo desenvolvido, o material documental referente ao ano de 1826, o qual já se encontra na Imprensa da Universidade do Paraná para publicação. b) - O projeto referente ao levantamento de fontes para a história demográfica do Paraná, sob a direção da Professôra Altiva Pilatti Balhana, teve prosseguimento com o exame, no Departamento do Arquivo de São Paulo, das dez caixas relativas à "População" do planalto curitibano. Foram sele- 
cionadas para microfilmagem cêrca de 6.000 peças, de recenseamento da população curitibana. Esta microfilmagem, dado o seu volume, ainda se encontra em parte sendo procedida no Serviço de Documentação da Reitoria da Universidade de São Paulo. c) - O projeto de pesquisa, sob a direção dos Professôres Altiva Pilatti Balhana e Brasil Pinheiro Machado, referente aos russos-brancos, recentemente estabelecidos nos Campos Gerais, teve prosseguimento. Conforme previsão inicial do Projeto, foi a pesquisa, no entanto, ampliada, de modo a incluir outros núcleos coloniais daquela área. Assim, foi possível uma análise preliminar da contribuição dos novos contingentes populacionais, para a mudança da estrutura agrária dos Campos Gerais, complementando os estudos feitos pelo Professor Brasil Pinheiro Machado, sôbre a formação e desagregação da estrutura tradicional. Os primeiros resultados desta pesquisa foram apresentados, na forma de comunicações pelos Professôres Brasil Pinheiro Machado e Altiva Pilatti Balhana, ao II Simpósio dos Professôres Universitários de História. d) - Continuando, do ano anterior, o trabalho de levantamento de fontes documentárias para a História do Paraná, o Professor Brasil Pinheiro Machado prosseguiu no exame e arrolamento dos inventários existentes nos Cartórios da Comarca de Castro, e iniciou o estudo e arrolamento dos documentos constantes do arquivo do Conselheiro Jesuino Marcondes de Oliveira e Sá, depositado na Biblioteca Pública do Paraná. Êsses mesmos trabalhos deverão ter prosseguimento no ano de 1963. 2 -Atividades Didáticas $-\underline{1 \text {-Cursos }}$ $\underline{\text { regulares }}=$ Embora o transtôrno motivado pela greve estudantil, sacrificados sobretudo os trabalhos práticos, notadamente o Seminário, as cadeiras e disciplinas do Curso de História funcionaram regularmente, havendo sido ministradas as aulas e os programas conforme as exigências legais. Os Professôres Brasil Pinheiro Machado e Cecília Maria Westphalen, sem quaisquer ônus para a Universidade, prelecionaram respectivamente as disciplinas Princípios de Sociologia e Introdução à História, durante o decorrer de todo o ano letivo. 2 - Palestras, Conferências e Concursos. Convidada pela Reitoria da Universidade do Paraná, a Professôra Cecília Maria Westphalen participou, no mês de abril, dos trabalhos da II Universidade Volante, havendo prelecionado 8 aulas de Técnicas do Ensino da História para professôres de Ensino Médio e Superior. Ainda a Professôra Cecília Maria Westphalen participou do Simpósio referente ao "Homem brasileiro e o desenvolvimento", realizado durante a VII Reunião da Socie- 
dade Brasileira para o Progresso da Ciência, havendo apresentado a comunicação sôbre "Analfabetismo e desenvolvimento". A Professôra Altiva Pilatti Balhana, no mês de novembro, proferiu no Centro de Estudos de História, palestra sob o título "Italianos no Paraná". O Professor Brasil Pinheiro Machado participou da Banca Examinadora do Concurso para provimento da Cátedra de Administração e Organização do Trabalho, da Faculdade de Ciências Econômicas da Universidade do Paraná. A Professôra Cecília Maria Westphalen participou da Banca Examinadora do Concurso de Doutoramento na Cadeira de História Moderna e Contemporânea, da Faculdade de Filosofia da Universidade de São Paulo. 3. II Simpósio dos Professôres Universitários de História - Aos Professôres do Departamento de História coube a tarefa de organizar e realizar o II Simpósio dos Professôres Universitários de História, promovido em Curitiba pela Associação dos Professôres Universitários de História, como parte integrante das comemorações do Cinquentenário da Universidade do Paraná. Inscreveramse ao II Simpósio 197 Professôres de todo o País e do Exterior, notadamente dos Estados Unidos, França, Espanha, Portugal, Bélgica e Itália. A êle compareceram 181 Professôres das diversas Faculdades de Filosofia e Faculdades de Ciências Econômicas brasileiras, e alguns Professôres estrangeiros. O II Simpósio revestiu-se de grande êxito cultural, e neste relatório devemos destacar a participação dos Professôres do Departamento de História da Faculdade de Filosofia da Universidade do Paraná, que apresentaram ali magníficos trabalhos, quais sejam: Professor Brasil Pinheiro Machado - "Contribuição ao estudo da história agrária do Paraná: Formação da estrutura agrária tradicional dos Campos Gerais;” Professôra Altiva Pilatti Balhana - "Contribuição ao estudo da história agrária do Paraná: Mudança na estrutura agrária dos Campos Gerais"; e Professor Oldemar Blasi - "Aplicação do método arqueológico na investigação da história agrária de Vila Rica do Espírito Santo". 4 -Associação dos Professôres Universitários de História - Por iniciativa dos Professôres do Departamento de História, foi organizado e instalado, sob a presidência do Professor Brasil Pinheiro Machado, o Núcleo Regional do Paraná, da Associação dos Professôres Universitários de História, reunindo Professôres dos Cursos de História, das demais faculdades de Filosofia e Faculdades de Ciências Econômicas do Paraná. Em assembleia da Associação dos Professôres Universitários de História, realizada durante o II Simpósio, foi 
a Professôra Cecília Maria Westphalen reeleita para a vice-Presidência

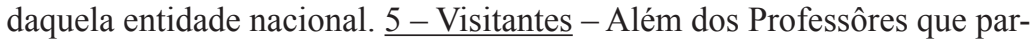
ticiparam do II Simpósio dos Professôres Universitários de História, destaca-se, no ano de 1962, a visita do Professor Doutor Fernand Vercauteren, da Universidade de Liège, que pronunciou no Departamento de História conferência sôbre "Le domaine au Moyen Age". 6 - Publicações - O Departamento de História iniciou no ano de 1962 a publicação do seu Boletim sob os auspícios do Conselho de Pesquisas da Universidade do Paraná, havendo já circulado o Boletim no 1 - História Moderna e Contemporânea - junho de 1962 - "Alfaias e jóias do antigo Colégio dos Jesuítas em Paranaguá". O n 2 do referido Boletim, com data de dezembro de 1962, já se encontra no prelo. 7 -Bolsistas e Estagiários - O Conselho de Pesquisas da Universidade do Paraná concedeu, no ano de 1962, Bolsas de Estudos à licenciada Odah Regina Guimarães Costa, que trabalha junto ao Projeto sôbre "O comércio do Paraná, através do pôrto de Paranaguá", e à Acadêmica Oksana Boruszenko que trabalha junto ao Projeto referente aos russos brancos dos Campos Gerais. Realizaram ainda Estágio de trabalhos e Estudos junto ao Departamento de História, o licenciado Américo Augusto da Costa Souto, e as Acadêmicas Luiza Beatriz Silveira Reis e Mitiko Okasaki. 8 - Biblioteca do Departamento - A Biblioteca do Departamento funcionou regularmente. Foram adquiridas novas obras e aumentado o seu acêrvo com a vinda de volumes da Biblioteca Central da Faculdade. O número de livros e outras publicações, neste ano de 1962, alcançou 713 volumes. Devemos ainda ressaltar o início de permuta com instituições congêneres, das publicações dos Professôres do Departamento de História. O número de consulentes alcançou a 437 leitores, sendo a sua maior concentração nos meses de agôsto e novembro. 9. Secretaria - Continuando embora sem um Secretário administrativo, a Secretaria do Departamento funcionou regularmente. No ano de 1962 foi extraordinário o movimento de correspondência, em virtude do II Simpósio dos Professôres Universitários de História. Foi grande também o movimento de correspondência originado do intercâmbio de publicações com entidades nacionais e estrangeiras. 10-Centro de Estudos de História -O Departamento de História incentivou o Centro de Estudos de História dos alunos do Curso de História - Uma delegação de alunos compareceu ao II Congresso da Federação Brasileira de Centros de Estudos de História, realizado em Salvador, sendo 
que todos os membros da Delegação apresentaram trabalhos que foram aprovados. Sob os auspícios do Conselho de Pesquisas da Universidade do Paraná, o Centro de Estudos de História iniciou a publicação da Revista de História destinada sobretudo a divulgar os trabalhos realizados pelos acadêmicos de História. Com a colaboração do Departamento de História, o Centro de Estudos de História realizou interessante Exposição retrospectiva e comemorativa do Cinquentenário da Universidade do Paraná, a qual depois foi, a pedido da Reitoria, exposta no saguão do prédio central da Universidade. O Centro de Estudos de História promoveu ainda uma série de palestras pelos Professôres do Curso e pelos próprios alunos. 11 Aquisições - Dado o grande volume de peças microfilmadas que deveriam ser lidas e transcritas, tendo em vista os projetos de pesquisa em andamento no Departamento de História, foi adquirido em 1962 um nôvo aparelho de leitura de micro-filmes. 12 - Mandato - Havendo já transcorridos, em novembro próximo passado, dois anos da criação do Departamento de História, a Professôra Cecília Maria Westphalen, na última reunião do ano letivo, entregou a direção do Departamento de História ao seu Conselho Diretor, o qual, porém, por unânimidade dos professôres presentes, renovou o seu mandato." As atividades do Departamento de História no ano de 1963, foram consignadas no relatório anual enviado à direção da Faculdade de Filosofia e que segue transcrito $=$ "Relatório das atividades do ano de 1963 - 1.0 - Atividades Didáticas - 1.1. Cursos regulares: As cadeiras e disciplinas do Curso de História funcionaram regularmente, havendo sido ministradas as aulas e os programas conforme as exigências legais. A adoção, para tôdas as cadeiras e disciplinas do Curso, dos horários compactos foi de grande proveito pedagógico, recomendando-se o mesmo critério para o ano seguinte. Os Professôres Brasil Pinheiro Machado e Cecilia Maria Westphalen, sem ônus para a Universidade, prelecionaram respectivamente as disciplinas Princípios de Sociologia e Introdução à História. A Professôra Cecília Maria Westphalen prelecionou ainda as disciplinas de Prática de Ensino de História e Prática de Ensino de Geografia. 1.2. Conferências, palestras, congressos: Convidada pela Reitoria da Universidade do Paraná, a Professôra Cecília Maria Westphalen participou da III e IV Promoções da Universidade Volante, realizadas respectivamente em abril e novembro do corrente ano, nas cidades de Maringá e Jacarezinho, havendo em ambas prelecionado 8 aulas de Orientação Metodológica da 
História, para Professôres de Ensino Médio e Superior. A Professôra Altiva Pilatti Balhana, no decorrer do mês de julho, participou em São Paulo do "Seminário sôbre assimilação cultural de imigrantes", sob a direção do Professor Egon Schaden, durante a VI Reunião Brasileira de Antropologia, havendo apresentado Comunicação, em colaboração com Oksana Boruszenko, sôbre "Problemas de aculturação nos Campos Gerais". Ainda a Professôra Altiva Pilatti Balhana pronunciou Conferência, no Círculo de Estudos Bandeirantes, no mês de agôsto,- conferência sôbre "Russos brancos nos Campos Gerais". O Professor Bento Munhoz da Rocha Neto pronunciou, no Círculo de Estudos Bandeirantes, no decorrer do mês de agôsto, Conferência sôbre "Regionalização e Reforma Agrária". A Professôra Cecília Maria Westphalen proferiu, ainda, na Biblioteca Pública do Paraná, Conferência sôbre "A História no método Lubienka-Lenval", no mês de abril do corrente ano. 1.3. Curso de Extensão Universitária: Sob o patrocínio da Reitoria da Universidade do Paraná e da Diretoria da Faculdade de Filosofia, o Departamento de História promoveu a realização de um Curso de Introdução ao Estudo da História, o qual foi prelecionado pela Professôra Maria Clara R. T. Constantino, da Faculdade de Filosofia de Marília. O referido Curso foi ministrado em 15 horas de aula, havendo sido frequentado com grande interêsse pelos alunos de todo o Curso de História, bem como por acadêmicos e Professôres de História de outras cidades, vindos especialmente para tal. 1.4. Publicações: O Departamento de História desenvolveu grande atividade no setor das publicações. No decorrer do ano circularam os "ANAIS do II Simpósio dos Professôres Universitários de História", bem como o Boletim n. ${ }^{\circ} 2$ - Departamento de História - dezembro de 1962 - "O pôrto de Paranaguá no ano de 1826 - Estudos de microconjuntura", o Boletim n. ${ }^{\circ} 3$ - Departamento de História - junho de 1963 - "Contribuição ao estudo da história agrária do Paraná - I - Formação da estrutura agrária tradicional dos Campos Gerais. II. Mudança na estrutura agrária dos Campos Gerais", o Boletim n. ${ }^{\circ} 4$ - Departamento de História - junho de 1963 - "Aplicação do método arqueológico no estudo da estrutura agrária de Vila Rica do Espírito Santo - Fênix - Paraná". 1.5. Estagiários: As acadêmicas Oksana Boruszenko, Luiza Beatriz Silveira Reis, Mitiko Okasaki e Carmen Mazanek realizaram estágio de estudos e trabalhos junto aos professôres do Departamento de História, em todo o decorrer do ano letivo, havendo participado dos Projetos de pesquisa em desen- 
volvimento. 1.6. Instrutor: O corpo de Professôres do Departamento de História foi acrescido com o aproveitamento da Licenciada Odah Regina Guimarães Costa nas funções de Instrutor da cadeira de História Moderna e Contemporânea, a qual passou a prestar seus serviços. 1.7. Biblioteca do Departamento: A Biblioteca do Departamento funcionou regularmente das 13 às 18 horas. Foram adquiridas novas obras e aumentado o seu acêrvo com a vinda de volumes da Biblioteca Central da Faculdade. O número de livros e outras publicações alcançou, no de 1963, 801 volumes. A Biblioteca manteve correspondência e permuta com 137 instituições. O número de consulentes alcançou 638 leitores, sendo que a sua maior concentração registrou-se nos meses de junho, outubro e novembro. 1.8. Secretaria: Embora sem contar com um Secretário Administrativo, a Secretaria do Departamento funcionou regularmente, sendo de destacar o movimento de correspondência originado do intercâmbio de publicações com entidades nacionais e estrangeiras. 1.9. Aquisições - Foram adquiridos, no decorrer do ano de 1963, um aparelho de leitura de micro-fichas, um epidiascópio, um projetor de slides e uma máquina de escrever. 1.10. Centro de Estudos de História: O Departamento de História incentivou os trabalhos do Centro de Estudos de História dos alunos do Curso de História. No primeiro semestre foi publicado o n. ${ }^{\circ} 2$ da Revista de História do Centro. Os membros da bancada paranaense apresentaram todos trabalhos ao III Congresso da Federação Brasileira de Centros de Estudos de História, os quais foram aprovados. No segundo semestre o Centro promoveu a realização de um Curso de Extensão, ministrados pelos economistas Eduardo José Daros e Charles Mueller, sôbre "Teoria do desenvolvimento econômico" e "Teoria dos ciclos econômicos". 2.0. Atividades de Pesquisa - 2.1 Projeto "Comércio Importador e Exportador do Paraná, através do pôrto de Paranaguá", sob a direção da Professôra Cecília Maria Westphalen: No decorrer do ano de 1963 foi completada a leitura e transcrição das peças microfilmadas de documentação existente no Departamento do Arquivo do Estado de São Paulo. Foi iniciada a elaboração estatística referente ao período 1837-1853. Foi também elaborada e redigida, como trabalho complementar face às evidências documentais encontradas, a Comunicação "Duas Vilas paranaenses no final do século XVIII", a qual se encontra pronta para publicação. 2.2. Projeto referente ao "Levantamento de fontes para a historia demográfica do Paraná", sob a direção da Prof. altiva Pilatti Balhana: A documen- 
tação coletada no ano anterior não teve ainda concluída a sua microfilmagem, dado o seu volume e os problemas acarretados pela mudança do Serviço de Documentação da Reitoria da Universidade de São Paulo. A parte já microfilmada, referente ao período - População - Curitiba - anos de 1765 a 1782, encontra-se em fase final de leitura e transcrição. 2.3. Projeto "Campos Gerais", sob a direção dos Professôres Brasil Pinheiro Machado e Altiva Pilatti Balhana: O desenvolvimento do Projeto, no corrente ano, deu especial ênfase ao estudo da comunidade menonita Witmarsum. Foram realizados trabalhos de campo naquela Colônia nos mêses de janeiro, fevereiro, março, abril, maio, junho, julho e novembro, cujos dados levantados estão sendo elaborados, no momento, em trabalho de gabinete. Sôbre os russos-brancos, estabelecidos nos Campos Gerais, foram já apresentados resultados parciais ao Seminário de Assimilação Cultural de Imigrantes, realizado em São Paulo. 2.4. Projeto referente ao "Levantamento de fontes para a história regional", sob a direção do Professor Brasil Pinheiro Machado: Teve prosseguimento o exame e arrolamento dos inventários existentes nos cartórios da Comarca de Castro, bem como o estudo e arrolamento dos documentos constantes do Arquivo do Conselheiro Jesuino Marcondes de Oliveira e Sá, depositado na Biblioteca Pública do Paraná. 2.5. Projeto referente à "Colonização ucraniana no Paraná", sob a orientação da Professora Altiva Pilatti Balhana e execução da Licenciada Oksana Boruszenko: O presente projeto foi iniciado no decorrer do ano com a coleta da bibliografia especializada, bem como foi iniciado o levantamento de dados na cidade de Prudentópolis. Nota prévia sôbre a imigração ucraniana no Paraná, foi publicada no n. ${ }^{\circ} 2$ da Revista de História, do Centro de Estudos de História, por Oksana Boruszenko." Concluído pela Prof. ${ }^{\mathrm{a}}$ Diretora o histórico da fundação do Departamento, bem como o registro das suas atividades didáticas e de pesquisa, nos anos de 1961, 1962 e 1963, passou a mesma à Ordem do Dia da presente sessão, qual seja: 1) - Relatório das atividades do ano de 1964 - 2) - Horários e programas para 1965 - 3) - Sugestões para 1965 - 4) - Comentários sôbre o desenvolvimento dos projetos de pesquisa pelos respectivos orientadores -5) - Assuntos gerais. Com a palavra a Professôra Diretora apresenta o Relatório das atividades do Departamento de História no ano de 1964, o qual segue transcrito: "Relatório das atividades do ano de 1964: 1.0 - Atividades didáticas: 1.1 . Cursos regulares - As cadeiras e disciplinas do curso de História funcio- 
naram normalmente, havendo sido ministradas as aulas e os programas conforme as exigências legais, e nos horários programados. Com a ausência da Professôra Cecília Maria Westphalen, colocada que foi à disposição do Gabinete do Senhor Ministro da Educação e Cultura, as disciplinas afetas à sua Cátedra foram prelecionadas pelos Instrutores Odah Regina Guimarães Costa e Jayme Antonio Cardoso. As cátedras de História do Brasil e de História Moderna e Contemporânea tiveram a seu cargo, respectivamente, sem quaisquer ônus para a Universidade, as disciplinas: Princípios de Sociologia ( $1^{\circ}$. ano curso de História) e História Política, Social e Econômica do Brasil ( $4^{\circ}$. ano do curso de Ciências Sociais); e Introdução à História $\left(1^{\circ}\right.$. ano do curso de História), Prática de Ensino ( $4^{\circ}$. ano do curso de História), e História Política, Social e Econômica Geral (4 ${ }^{\circ}$. ano do curso de Ciências Sociais). 1.2 - Viagens, conferências, palestras, congressos, concursos: Sem quaisquer ônus para a Universidade do Paraná, durante os meses de janeiro e fevereiro do corrente ano, realizaram estágio de pesquisa em arquivos portugueses, e viagem cultural a outros países da Europa Ocidental, as Professôras Cecília Maria Westphalen e Altiva Pilatti Balhana. Convidada pelo Professor Fernand Braudel, Diretor da $6^{\text {a }}$. sessão da École Pratique des Hautes Études, da Universidade de Paris, a Professôra Cecília Maria Westphalen, ali proferiu conferência a 22 de janeiro sôbre o tema "A pesquisa histórica na Universidade do Paraná", no Seminário sôbre a América Latina. Os Professôres Brasil Pinheiro Machado e Altiva Pilatti Balhana, a convite da Faculdade de Filosofia de Ponta Grossa, ali proferiram respectivamente, nos dias 7 e 9 do mês de outubro, as seguintes conferências: "Formação da historiografia brasileira", "Colonização recente nos Campos Gerais". Ainda os Professôres Brasil Pinheiro Machado e Altiva Pilatti Balhana, em curso de História do Paraná realizado sob o patrocínio da Secretaria de Educação e Cultura, proferiram no mês de setembro, as seguintes conferências: "Política paranaense", "O imigrante na formação étnica do Paraná". A Professôra Odah Regina Guimarães Costa participou, como Professôra, do Curso de Treinamento Básico para Professôres de Ensino Médio, promovido em Curitiba pela Cades do Ministério da Educação e Cultura. O Professor Brasil Pinheiro Machado participou, no mês de novembro, da Banca Examinadora de Concurso para Docência-Livre da cadeira de História do Brasil da Faculdade de Filosofia da Universidade de São Paulo. A Prof. ${ }^{a}$ Cecília Maria West- 
phalen, representando o Estado do Paraná, participou no corrente mês de dezembro, da II Reunião Conjunta do Conselho Federal de Educação com os Conselhos Estaduais de Educação. Ainda a Professôra Cecília Maria Westphalen participou, no mês de novembro, de Banca Examinadora de Concurso para os cargos de Professor Licenciado do serviço público estadual do Paraná. A Professôra Odah Regina Guimarães Costa, no mês de novembro, prestou concurso para cargo de Professor Licenciado do Estado do Paraná, havendo sido aprovada. 1.3. Publicações: Dadas as dificuldades encontradas pelo Conselho de pesquisas da Universidade do Paraná, em relação à concessão de verbas, não foi possível ao Departamento de História, embora concluídos diversos trabalhos, manter o mesmo ritmo de publicações do ano anterior. 1.4. Estagiários: Os acadêmicos Luiza Beatriz Silveira Reis e Mitiko Okasaki realizaram estágio de estudos e trabalhos junto aos professôres do Departamento de História, no decorrer do presente ano letivo, participando das suas atividades, bem como a licenciada Oksana Boruszenko que participou de projetos de pesquisa em desenvolvimento. 1.5. Instrutor: O corpo de Professôres do Departamento de História foi acrescido com o aproveitamento do Licenciado Jayme Antonio Cardoso, nas funções de Instrutor da cadeira de História Moderna e Contemporânea, a qual passou a prestar serviços. 1.6. Biblioteca: A Biblioteca do Departamento funcionou regularmente das 13 às 18 horas. O número de consulentes alcançou 847 leitores, sendo que a sua maior concentração registrou-se nos meses de maio, junho, setembro e outubro. A Biblioteca manteve correspondência e intercâmbio com várias instituições, registrando-se porém menor movimento que no ano anterior, em virtude da ausência de publicações no ano de 1964. Nova estante foi acrescida ao acêrvo da Biblioteca, bem como novas obras vindas da Biblioteca Central da Faculdade, alcançando o livro de registros 886 volumes. 1.7. Secretaria: Embora sem contar com Secretário Administrativo, a Secretaria do Departamento funcionou regularmente. 1.8. Centro de Estudos de História: pelos mesmos motivos que não se realizaram publicações do Departamento, também não saiu o n. ${ }^{\circ} 3$ da Revista de História, do Centro de Estudos de História, cujos originais encontram-se na Imprensa Universitária. O Departamento de História, pelos meios ao seu alcance, incentivou os trabalhos do Centro de Estudos de História que realizou as seguintes atividades: conferência do Professor Reinhardt Maack, sôbre "África de Hoje"; conferência sôbre "Introdução à Numismática", 
pelo colecionador Helio Lisboa Guimarães; conferência sôbre "Arqueologia Brasileira" com o Professor Igor Chmyz; conferência sôbre "Organização Social e Política da Alemanha" e o "Muro de Berlim" com H. Zimmermann; conferência sôbre "Aspectos da Grécia Moderna", com o Professor Laertes Munhoz; viagem ao Museu de Paranaguá e ali conferência sôbre o "Museu de Paranaguá", com o Professor José Loureiro Fernandes; e a publicação do $1^{\circ}$. número do jornal "Tópicos históricos". 1.9. Visitas: o Departamento de História recebeu em setembro, a visita do Professor titular da cadeira de História Econômica da Universidade de Colonia, Hermann Kellenbenz, que aqui proferiu Conferência sôbre "Os alemães no Comércio do Brasil no século XVII" e participou com os professôres do Departamento de Seminário sôbre "O moderno pensamento histórico alemão". 2.0 Atividades de pesquisas - 2.1. Projeto "Comércio Importador e Exportador do Paraná, através do pôrto de Paranaguá", sob a direção da Professôra Cecília Maria Westphalen. Em janeiro de 1964, sem ônus para a Universidade do Paraná, foram visitados, em Portugal, o Arquivo Histórico Ultramarino, o Arquivo Nacional da Torre do Tombo, o Fundo Histórico Municipal de Lisboa, o Arquivo Histórico do Ministério de Finanças, a Seç̧ão Histórica da Biblioteca Nacional e o Arquivo Geral da Alfândega de Lisboa, realizando-se assim a necessária pesquisa de fontes primárias existentes em Arquivos portugueses, onde foram microfilmadas e já lidas e transcritas, cêrca de 75 peças, diretamente relacionadas com o projeto. $\mathrm{O}$ ano de 1964 foi de grande impulso para o presente projeto uma vez que além dos arquivos portugueses foram também trabalhados os Arquivos do Rio de Janeiro, tais como o Arquivo Nacional, o Arquivo Histórico do Itamaraty, a Secção de Manuscritos da Biblioteca Nacional, a Secção de Manuscritos do Instituto Histórico e Geográfico Brasileiro, o Real Gabinete Português de Leitura, as Bibliotecas do Ministério da Fazenda, da Agricultura, do I.B.G.E., da Alfândega do Rio de Janeiro e outras, onde foram microfilmadas cêrca de 3.000 peças de documentação relativa ao projeto, as quais em parte se encontram em fase de leitura e transcrição, e outras sendo ampliados os microfilmes, pela dificuldade e urgência de leitura. Destarte restam apenas os Arquivos do Prata a serem levantados para que se complete o levantamento de fontes primárias imprescindíveis à elaboração do trabalho. Neste ano de 1964 foi ainda iniciado o fichário sistemático, dado o volume de material levantado, das fontes relativas ao 
comércio do Paraná no século XIX. 2.2. Projeto "Levantamento de fontes para a história demográfica do Paraná", sob a direção da Professôra Altiva Pilatti Balhana. A documentação coletada, no ano de 1962, no Departamento do Arquivo do Estado de São Paulo, não teve concluída a sua microfilmagem, em virtude de problemas do próprio serviço de Documentação da Reitoria da Universidade de São Paulo. Porém, a parte já microfilmada, referente ao período: População - Curitiba - Caixa T.C. 203 - 1765 a 1782, teve concluída a sua leitura e transcrição. Também, em relação a êste Projeto foram visitados e pesquisados os arquivos portugueses e nacionais referidos no item 1.1, coletando-se cêrca de 450 peças relativas à população do Paraná no século XIX e final do século XVIII. 2.3. Projeto "Campos Gerais", sob a direção dos Professôres Brasil Pinheiro Machado e Altiva Pilatti Balhana: Para melhor compreensão dos problemas da região dos Campos Gerais, julgou-se necessário empreender uma análise aprofundada, por especialistas de várias disciplinas, das comunidades daquela área. Assim prosseguiu o estudo da colônia menonita Witmarsum, segundo plano elaborado com base nos levantamentos já efetuados e incluindo a colaboração de pesquisadores das diferentes Ciências Sociais (sociólogo, historiador, economista, geógrafo, etc.). A estas disciplinas foi somado o trabalho de pesquisadores do Instituto de Geologia da Universidade que estudaram a paisagem natural, proporcionando assim visão global da comunidade. $\mathrm{O}$ levantamento de dados para a análise da estrutura demográfica foi concluído. Foram efetuados levantamentos para o estudo da estrutura agrária, compreendendo áreas cultivadas e regimes agrários, etc. Foram organizados os formulários para o estudo da organização e estratificação social da comunidade. 2.4 - Projeto "Levantamento de fontes para a história regional", sob a direção do Professor Brasil Pinheiro Machado: O projeto teve prosseguimento com o exame de arquivos judiciários das Comarcas de Castro e Lapa, bem como com a análise dos documentos do Arquivo do Conselheiro Jesuino Marcondes, depositado na Biblioteca Pública do Paraná. Foram ainda examinadas fontes bibliográficas e documentais relativas ao ouro em Paranaguá. 2.5. Projeto "Colonização ucraniana no Paraná", sob a orientação da Professôra Altiva Pilatti Balhana e execução da licenciada Oksana Boruszenko. No decorrer do ano de 1964 teve prosseguimento o levantamento de dados bibliográficos relativos aos ucranianos antes de emigrarem, bem como foram visitados 17 núcleos coloniais ucranianos no 
município de Prudentópolis, para a coleta do material empírico necessário à reconstrução das fases dessa imigração, bem como histórias de vida $\mathrm{e}$ histórias de casos e autobiografias de imigrantes. 2.6. Projeto Preço de terras na região cafeeira do Paraná', sob a orientação da Prof. ${ }^{a}$ Cecília Maria Westphalen e execução da Prof. ${ }^{a}$ Odah Regina Guimarães Costa: O presente projeto, embora realizado prévio levantamento de fontes bibliográficas, não entrou em execução em virtude de dificuldades várias, como ausência da Professora Orientadora, sobrecarga de trabalhos do Departamento de História, e ainda insuficiência de dotações. As possibilidades do momento, porém, permitiram sob a orientação e execução das mesmas Professôras, e desenvolvimento de outro Projeto mais viável na ocasião e aprovado pelo Conselho do Departamento, qual seja - "A ação empresarial do Barão do Sêrro Azul na conjuntura paranaense - 1874. 1894", do qual foi realizado o trabalho de levantamento bibliográfico e documentação. 2.7. Projeto "Comédias de Plauto", execução da Professora Neusa de Castro Guimarães: O Projeto teve início no corrente ano e tem por objetivo a análise das instituições sociais e as condições culturais da vida romana através das obras de Plauto." Apresentado o relatório foi o mesmo aprovado pelos professôres presentes, devendo na forma de costume ser encaminhado aos órgãos diretores da Faculdade de Filosofia e do Conselho de Pesquisas da Universidade do Paraná. A seguir a Professôra Diretora colocou em discussão o projeto de horários de aulas das diversas disciplinas de História, bem como do Curso de História para o ano letivo de 1965 (mil novecentos e sessenta e cinco), tendo sido, após consultados os respectivos professôres, aprovado. Ligado a êsse assunto ficou resolvido também, em virtude do reduzido número de salas de aulas para o curso de História, no sexto andar, solicitar a concessão das salas de $\mathrm{n}^{\circ} \mathrm{s} 605$ e 612 nos horários em que se acharem vagas, o que serviria para reunir as turmas no $6^{\circ}$. andar, trazendo benefícios de ordem didática. - Posteriormente, a Diretora do Departamento falou sôbre a inconveniência dos quartanistas dos cursos de Ciências Sociais e Geografia cumprirem programas semestrais de algumas cadeiras do quarto ano de História; após discussão, ficou determinado que se proporia o cumprimento de um ano para os quartanistas daqueles cursos, juntamente com o quarto ano de História, da disciplina de História Econômica, Social e Política Geral e do Brasil, nas cadeiras de História do Brasil e História Contemporânea. - Em seguida, acusando o recebimento da circu- 
lar do Professor Diretor da Faculdade, em que solicita matéria e bibliografia das diversas disciplinas, o que, conforme a Lei de Diretrizes e Bases da Educação Nacional, seria o plano de curso, a Diretora solicitou que os Professôres regentes de disciplinas providenciassem a entrega do programa e bibliografia das diversas disciplinas até o dia quinze próximo. Também para essa data, ficou determinado que cada Professor fizesse a entrega de um sucinto relatório das suas atividades no ano letivo que finda. - Pediu a palavra a Professôra Odah Regina Guimarães Costa para expor suas sugestões, tendo em vista suas observações durante a regência das disciplinas de Introdução à História no primeiro ano, História Contemporânea no terceiro ano e Prática de Ensino da História no quarto ano. Inicialmente, observadas as necessidades da cadeira de Prática de Ensino, sugeriu que mais uma vez fôsse solicitada a criação de um Colégio de Aplicação na Faculdade; em seguida pede a organização no Departamento de um setor de material didático áudio-visual, para o qual os alunos teriam livre acesso; Sugeriu também que se tomasse providência para que fossem adquiridos algumas coleções de livros didáticos de História Geral e História do Brasil para o primeiro e segundo ciclos do curso secundário, para uso dos quartanistas nas aulas práticas de estudos dirigidos, e que essas sugestões fossem atendidas para o próximo ano letivo; posteriormente sugeriu a ampliação do horário para as sessões de Prática de Ensino, pelo menos no segundo semestre, para que houvesse mais tempo para as aulas práticas e que houvesse obrigatoriedade de frequência para essas aulas; com relação às suas disciplinas do terceiro e primeiro ano teceu considerações em tôrno dos respectivos programas. Tomando a palavra a Professôra Diretora, salientou a impossibilidade de dedicar-se maior atenção à Prática de Ensino, disciplina cujos encargos são do Departamento de Didática, porque a falta de tempo e pessoal acarretaria sacrifício das disciplinas históricas; sôbre os materiais solicitados tomar-se-iam as medidas necessárias; sôbre a frequência, que esta seria observada com rigidez durante os trabalhos e as aulas práticas; e, ainda sôbre o Colégio de Aplicação, far-se-ia um apêlo à direção da Faculdade comunicando o pensamento do Departamento a respeito do assunto. Em virtude de já ter passado das treze horas, a Presidente da sessão suspendeu a mesma, convocando os senhôres professôres para as quinze horas do dia seguinte. - Às quinze horas do dia três de dezembro, foi reiniciada a sessão presentes os mesmos professôres. - Com a palavra a 
Professôra Diretora comunicou que desde o dia $1^{\circ}$. do corrente, passou a exercer as funções de auxiliar de pesquisas bibliográficas a Professôra Rosane Filizola, aluna do Curso de Biblioteconomia, solicitando a Professôra Diretora autorização para que a mesma seja remunerada por serviços extraordinários e segundo as verbas destinadas àquelas pesquisas. A seguir, de acôrdo com a ordem do dia, os senhores professôres presentes teceram considerações acêrca do andamento dos seus respectivos projetos de pesquisa. O primeiro a ser comentado foi aquêle relativo ao "Comércio do Paraná através do pôrto de Paranaguá", sob a responsabilidade da Professôra Cecília Maria Westphalen. Tomando a palavra a Professôra Altiva Pilatti Balhana, disse que sôbre o projeto de Levantamento de fontes para a história demográfica do Paraná, foram feitas consultas no Arquivo Ultramarino em Lisboa, no Arquivo Nacional, na Biblioteca Nacional, estando os trabalhos de microfilmagem em São Paulo sem andamento normal, em virtude das dificuldades para transportar os documentos até a Cidade Universitária e não tendo entrado em funcionamento o serviço de microfilmagem do Arquivo do Estado de São Paulo, encontra-se atrasada a execução do projeto. - Em seguida o Professor Brasil Pinheiro Machado, sôbre o projeto da História Regional, disse ter feito e estar fazendo várias consultas a arquivos judiciários. - Relativamente ao projeto sôbre os Campos Gerais, a Professôra Altiva Pilatti Balhana disse estar sendo dada ênfase à comunidade menonita de Wittmarsum durante êsse período, procurando organizar os trabalhos num sentido multidisciplinar, o que tem sido feito não sem dificuldades, havendo ainda a colaboração de um pesquisador da Universidade norte-americana da Flórida para o setor religioso do projeto; que tem sido feito levantamento de documentação bibliográfica, dos menonitas antes de chegarem ao Brasil, havendo material no Departamento de Estatística para coordenação sôbre a estrutura demográfica, composição, número de população, e também geológico e fitogeográficos já na fase de mapeamento. - Tomando a palavra o Professor Brasil Pinheiro Machado, quiz salientar que o projeto "Campos Gerais" visa o estudo da mudança social, agrária, nos Campos Gerais, não só com a introdução do elemento estrangeiro, mas também a forma evolutiva da velha sociedade tradicional, que deverá continuar o estudo da sociedade tradicional na sua evolução e que para isso procurar-se-ia os muitos recantos onde ainda pode ser sentida a sociedade tradicional. - Com respeito ao projeto e pesquisas sôbre os ucranianos, a 
Professôra Oksana Boruszenko disse estar empenhada na seleção de bibliografia sôbre êsse grupo étnico antes de emigrarem para o Brasil, e que considera bom o material conseguido nesse ano, tendo visitado ainda dezessete núcleos ucranianos em Prudentópolis, continuando os trabalhos de coletas de dados. - Sôbre o projeto e pesquisas dos preços de terras da região cafeeira, a Professôra Odah Regina Guimarães Costa disse estar prejudicado nesse ano pelas suas funções de magistério no curso; ainda o seu trabalho sôbre o Barão do Cêrro Azul, disse estar em processo de coleta final em Curitiba, devendo a seguir pesquisar os arquivos de São Paulo e Rio de Janeiro. Depois tomou a palavra a Professôra Neusa de Castro Guimarães para comunicar que está em adiantado estágio o seu trabalho sôbre as Comédias de Plauto, havendo de sua parte a pretensão de conclusão em mil novecentos e sessenta e cinco. - Retomando a palavra a Presidente da Sessão e Diretora do Departamento, falou sôbre a ausência de publicação do Departamento nesse ano e que poderiam ser intensificados os trabalhos no sentido de realizá-las no próximo ano. - Terminou por comunicar aos membros do Departamento que os trabalhos do mesmo se alongariam até o dia vinte de dezembro, quando haveria uma interrupção durante as festas de fim de ano. Nada mais havendo a tratar, a Presidente declarou livre a palavra, e como ninguém quizesse dela fazer uso, agradeceu a presença de todos e encerrou a presente sessão da qual eu, Jayme Antonio Cardoso, Secretário "ad hoc", lavrei a presente ata que após leitura e aprovação na próxima sessão, será devidamente assinada pela Presidente, por mim, Secretário, que a escrevi, e pelos demais membros dêste Departamento.

Cecília Maria Westphalen

Neusa de Castro Guimarães

Altiva Pilatti Balhana

Brasil Pinheiro Machado

Odah Regina Guimarães Costa

Jayme Antonio Cardoso 